\title{
Transient Osteoporosis of the Hip: A Case Report
}

\author{
Selda Ciftci, () Beril Dogu, (1) Rana Terlemez, (1) Figen Yilmaz, (1) Banu Kuran
}

Department of Physical Medicine and Rehabilitation, University of Health Sciences Turkey, Sisli Hamidiye Etfal Teaching and Research Hospital, Istanbul, Turkey

\begin{abstract}
Transient osteoporosis of the hip, idiopathic, is a table, beginning with hip pain without a history of trauma, usually self-limiting and seen in middle-aged men and pregnant women. In this case report, a male patient who was admitted because of hip pain and detected transient osteoporosis go the hip was discussed. The purpose of the case presentation is to emphasize the necessity of transient osteoporosis of the hip in the differential diagnosis of sudden onset of hip pain and to review the literature on this subject.

Keywords: Bone marrow edema; magnetic resonance imaging; pregnancy; transient osteoporosis of the hip.

Please cite this article as "Ciftci S, Dogu B, Terlemez R, Yilmaz F, Kuran B. Transient Osteoporosis of the Hip: A Case Report. Med Bull Sisli Etfal Hosp 2020;54(4):505-507".
\end{abstract}

$T$ ransient osteoporosis of the hip $(\mathrm{TOH})$ is generally and idiopathic disease with a good prognosis and self-limiting. [1] $\mathrm{TOH}$ is seen in men in the $4^{\text {th }}$ or $5^{\text {th }}$ decay of life, in pregnant women in the $3^{\text {rd }}$ trimester and in the early postpartum period. The most important method for diagnosis after clinical history and examination is magnetic resonance imaging (MRI). ${ }^{[2,3]}$ In this case report, the diagnosis and treatment of $\mathrm{TOH}$ will be mentioned over the male case with $\mathrm{TOH}$.

\section{Case Report}

A 43-years-old male patient was admitted to our outpatient clinic with complaints of left hip pain that worsened in the age of about a month and difficulty walking. When the patient's history is examined, we learned that the pain started suddenly, there was no trauma, the pain was especially severe when walking. He was smoking, could not drink alcohol, and had no known illness in his history. There was no medication he used all the time. He received medi- cal treatment for pain and did not benefit.

In the examination of the patient, it was detected that hip range of motionwas open on the right, $20^{\circ}$ of the internal rotation on the left, and was open in other directions. In addition, the FABER test on the left was evaluated as positive. It was observed that he avoided giving it to his left leg while walking.

In the laboratory examinations, C-Reactive Protein (CRP) level was $6 \mathrm{mg} / \mathrm{L}$, 25-Hydroxy Vitamin D level was $20.6 \mathrm{ng}$ $/ \mathrm{mL}$, hemogram and wide biochemistry tests were within normal limits. There was no obvious pathology in the pelvis anteroposterior radiography. Thereupon, an MRI of the hip was requested as an advanced examination. MRI showed intense medullary edema in the femoral head and neck, lobulation fluid in the left hip joint and a small loose body (Figs. 1, 2). TOH was considered in the foreground in the patient without a history of trauma. Thereupon, bone mineral density (BMD) was measured using Dual-Energy X-Ray Ab-

Address for correspondence: Selda Ciftci, MD. Turkiye Saglik Bilimleri Universitesi, Sisli Hamidiye Etfal Egitim ve Arastirma Hastanesi, Istanbul, Turkey

Phone: +90 5557775887 E-mail: seldavd@gmail.com

Submitted Date: October 30, 2018 Accepted Date: April 29, 2019 Available Online Date: December 11, 2020

${ }^{\circ}$ Copyright 2019 by The Medical Bulletin of Sisli Etfal Hospital - Available online at www.sislietfaltip.org

OPEN ACCESS This is an open access article under the CC BY-NC license (http://creativecommons.org/licenses/by-nc/4.0/). 


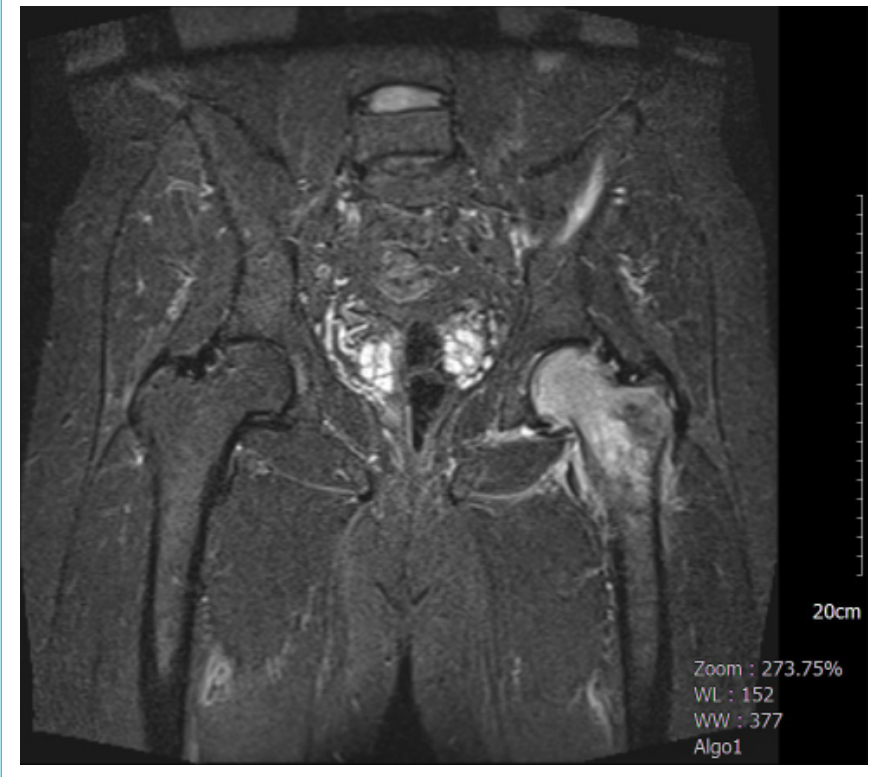

Figure 1.T1-Turbo inversion recovery magnitude (TIRM) coronal MRI.

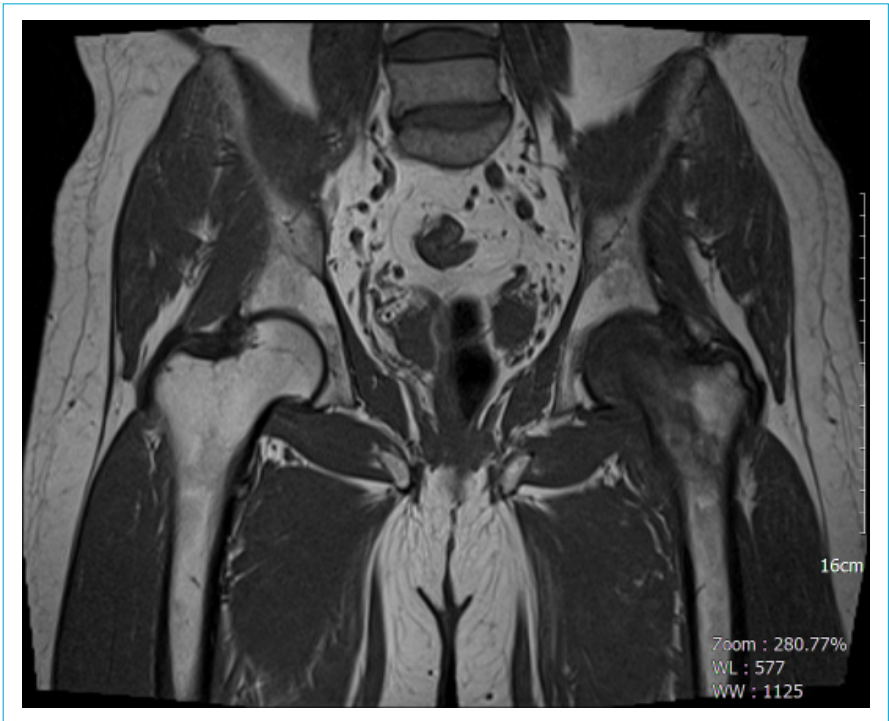

Figure 2. T1-Turbo spin-echo (TSE) coronal MRI.

sorptiometer (DXA), lumbar 2-4 T-score was -1.3 and femoral neck T-score was -1.7.

Conservative treatment was planned first. Rest was recommended to the patient, the use of a walking aid device was recommended to reduce the load on the femoral head, and exercises were demonstrated. Non-steroidal anti-inflammatory drug (NSAID) treatment was initiated for pain control. The ignition of bisphosphonate therapy was recommended but was not initiated because the patient did not want to use it. Calcium carbonate + cholecalciferol tablet and vitamin $D$ drop treatment were added, and the outpatient clinic was called after one month. Patient's consent was obtained for this study.

\section{Discussion}

TOH is an uncommon hip pain picture that is generally selflimited, Sean in middle-aged men and pregnant women, and begins hip pain without a history of trauma. ${ }^{[4]} \mathrm{TOH}$ was first described in 1959 by Curtiss and Kincaid in pregnant women in the third trimester with unilateral bilateral hip pain. They observed demineralization in the femoral head and the femoral neck in radiological imaging and observed that it resolved spontaneously after a few months. ${ }^{[5]}$ In 1988, Wilson et al. named the same clinical picture as 'Transient Tissue Edema Syndrome' and reported that BMD was normal or osteopenic when looking at their BMD with DXA, and they reported that there were hypointense signal changes in $\mathrm{T} 1$ sequence and hyperintense signal changes T2 and STIR sequences in MRI. ${ }^{[6]}$ In the literature, we see that TOH is named Temporary Bone Edema Syndrome, Transient Mobile Osteoporosis, Regional Transient Osteoporosis has been reported in the knee, ankle, foot, vertebra and shoulder.

$\mathrm{TOH}$ is divided into three phases. In the first stage, there is edema in the bone tissue together with acute hip pain, while in the second stage, it is seen that the resorption of the bone tissue increases and demineralization occurs. In the third stage, the disease is observed to regress clinically and radiologically ${ }^{[8,9]}$ With correct conservative treatment, recovery is seen in an average of six months. ${ }^{[10]}$

Although pregnancy is the most common risk factor reported for $\mathrm{TOH}$, when the literature is reviewed, it has been observed that the incidence is higher in men and the reported median age is $40 .{ }^{[4]}$ Rarely, it may occur due to trauma, alcohol consumption, smoking, corticosteroids, hyperthyroidism, hyperphosphatemia, low testosterone and vitamin D levels, vascular pathologies, inflammation, drug use or osteogenesis imperfecta. ${ }^{[1]}$

While there is a decrease in BMD in patients with $\mathrm{TOH}$, its relation with bone edema and micro-fracture is not clear. While an increase in bone turnover markers is detected in the biopsy performed from the lesion area, serum concentration levels do not increase. ${ }^{[7,12]}$

MRI is the best method to show TOH. MRI may show ede$\mathrm{ma}$ in the bone within the first 48 hours after symptoms begin. ${ }^{[9]}$ It allows exclusion of malignancy, osteomyelitis and inflammatory arthritis. T1 sequence is isointense, T2 and STIR sequences hyperintense, homogeneous pattern, diffuse edema with no clear boundaries. Here, stress fracture and vascular necrosis (AVN) should be considered in the differential diagnosis. While there is an irregular line in a stress fracture, deformity, crescent sign, focal and subchondral changes in the femoral head in AVN may facilitate the diagnosis. In addition, risk factors in the etiology 
of AVN may also be guiding. ${ }^{[10]}$

Treatment of $\mathrm{TOH}$ is primarily conservative. While reducing bone resorption, it recognizes the time required for regeneration. The pain may arise from increased intraosseous pressure, venous hypertension, increased focal bone turnover, micro-fracture and periosteal irritation. ${ }^{[7]}$ Conservative treatment consists of minimal weight-bearing, rating, the use of devices, such as walking canes, physical therapy methods, such as hot pack, ultrasound, interferential current, and the use of analgesics. ${ }^{[10]}$ We see that bisphosphonate, calcitonin and teriparatide have been used as medical treatment in small-scale, randomized and uncontrolled case studies in the literature. Although the is no clear guideline on the duration of use, it should be kept in mind that bisphosphonate treatment may lead to fetal malformations in pregnant women with TOH. ${ }^{[10,13]}$ Since calcitonin cannot pass through the placenta, its use in pregnant women is safer. ${ }^{[14]}$ While core decompression therapy gives successful results in AVN, it has not been shown to be superior to medical treatment in $\mathrm{TOH}$.

Although $\mathrm{TOH}$ is generally self-limiting, sub-capital fracture and femoral neck fracture can be seen, tases with AVN have been reported in the literature. ${ }^{[10,15]}$

To sum up, TOH should also be considered in the differential diagnosis of hip pain. The diagnosis should be made clearly with MRI and conservative treatment should be administered in the foreground. However, larger and more controlled studies are needed for medical treatment.

\section{Disclosures}

Informed Consent: Written informed consent was obtained from the patient for the publication of the case report and the accompanying images.

Peer-review: Externally peer-reviewed.

Conflict of Interest: None declared.

Authorship Contributions: Concept - S.C.; Design - B.D.; Supervision - F.Y., B.K.; Materials - R.T.; Data collection \&/or processing - S.C.; Analysis and/or interpretation - B.D., R.T.; Literature search - S.C.; Writing - S.C.; Critical review - F.Y., B.K.

\section{References}

1. Mirza R, Ishaq S, Amjad H. Transient osteoporosis of the hip. J Pak Med Assoc 2012;62:196-8.

2. Korompilias AV, Karantanas AH, Lykissas MG, Beris AE. Transient osteoporosis. J Am Acad Orthop Surg 2008;16:480-9. [CrossRef]

3. Pande K, Aung TT, Leong JF, Bickle I. Transient Osteoporosis of the Hip: A Case Report. Malays Orthop J 2017;11:77-8. [CrossRef]

4. Rajak R, Camilleri J. An unusual cause of hip pain. BMJ Case Rep 2011;2011:bcr0720114456. [CrossRef]

5. Curtiss PH Jr, Kincaid WE. Transitory demineralization of the hip in pregnancy. A report of three cases. J Bone Joint Surg Am 1959;41A:1327-33. [CrossRef]

6. Wilson AJ, Murphy WA, Hardy DC, Totty WG. Transient osteoporosis: transient bone marrow edema? Radiology 1988;167:757-60.

7. Patel S. Primary bone marrow oedema syndromes. Rheumatology (Oxford) 2014;53:785-92. [CrossRef]

8. Cano-Marquina A, Tarín JJ, García-Pérez MÁ, Cano A. Transient regional osteoporosis. Maturitas 2014;77:324-9. [CrossRef]

9. Szwedowski D, Nitek Z, Walecki J. Evaluation of transient osteoporosis of the hip in magnetic resonance imaging. Pol J Radiol 2014;79:36-8. [CrossRef]

10. Asadipooya K, Graves L, Greene LW. Transient osteoporosis of the hip: review of the literature. Osteoporos Int 2017;28:1805-16.

11. Rader CP. Transient osteoporosis and osteonecrosis of the femoral head. Risk factors, classification and differential diagnosis. [Article in German]. Orthopade 2007;36:423-4, 426-9. [CrossRef]

12. Berger CE, Kröner AH, Minai-Pour MB, Ogris E, Engel A. Biochemical markers of bone metabolism in bone marrow edema syndrome of the hip. Bone 2003;33:346-51. [CrossRef]

13. O'Sullivan SM, Grey AB, Singh R, Reid IR. Bisphosphonates in pregnancy and lactation-associated osteoporosis. Osteoporos Int 2006;17:1008-12. [CrossRef]

14. Laktasic-Zerjavic N, Curkovic B, Babic-Naglic D, Potocki K, Prutki $M$, Soldo-Juresa $D$. Transient osteoporosis of the hip in pregnancy. Successful treatment with calcitonin: a case report. [Article in German]. Z Rheumatol 2007;66:510-3. [CrossRef]

15. Berman N, Brent H, Chang G, Honig S. Transient osteoporosis: Not just the hip to worry about. Bone Rep 2016;5:308-11. [CrossRef] 